Est Ag 47 (2012) 101-122

\title{
El matrimonio nace... el matrimonio muere... Dos posiciones de cara al fracaso conyugal
}

\author{
J. SiLvio Botero G., CSsR.
}

RESUMEN: La reflexión sobre "El matrimonio nace... el matrimonio muere..." surgió del hecho de una confrontación entre la visión de Benedicto XVI y la postura de un diario italiano (Il Corriere della Sera) respecto del matrimonio. La Iglesia Católica mira al matrimonio en el momento de su nacimiento, el Estado civil lo mira en su momento final. La Iglesia católica ha estado tradicionalmente de parte de la indisolubilidad del matrimonio, mientras que el derecho civil, en general, mira a la posibilidad del divorcio. Al intentar hoy resolver el conflicto, se presentan algunas alternativas nuevas que miran a la posibilidad de conciliar el derecho con la pastoral, especialmente en lo que respecta a la indisolubilidad del matrimonio.

ABSTRACT: This reflection on "Marriage is born... marriage dies" arose from a confrontation between the vision of Benedict XVI and an italian newspaper( $I l$ Corriere della Sera) with respect to marriage. The catholic church has traditionally been part of the indissolubility of marriage. While the civil law, in general, look at the possibility of divorce. In attempting to resolve the conflict today, now are some alternatives that look at the possibility or reconciling the right with pastoral care, especially as regards the indissolubility of marriage.

\section{Introducción}

El 29 de Enero (2010) Benedicto XVI inauguraba el Año Judicial de la Rota Romana con la audiencia concedida a los Oficiales y Colaboradores de este Tribunal Eclesiástico; el discurso del Papa a la Rota Romana en esta ocasión rondaba en torno a 'la capacidad de toda persona de casarse en virtud de su misma naturaleza de varón o de mujer; sólo en presencia de una anomalía psíquica que perturbe gravemente el uso de la razón o la fa- 
cultad crítica y electiva en relación a graves decisiones, de modo especial, como también la imposibilidad de atender a las obligaciones inherentes al matrimonio, se podría hipotizar una verdadera incapacidad'1.

Con ocasión de este discurso del Papa a la Rota Romana un diario italiano (Il Corriere della Sera, 30 Enero 2010) hacía un comentario breve pero llamativo: "La necesidad de la verdad acerca del comienzo (y del final) de un matrimonio". Entre otras cosas, el articulista (M. Ventura) escribía: "en el tribunal eclesiástico la iglesia busca la verdad del matrimonio que nace; el Estado, en cambio, busca la verdad del matrimonio que muere. La iglesia para declarar la nulidad se pregunta: ¿el matrimonio fue válido o inválido?. El divorcio del Estado se interroga acerca de si el matrimonio está vivo todavía o si ya murió"2.

Esta aparente contraposición (el matrimonio nace..., el matrimonio muere) pide una aclaración: no obstante la revisión del viejo Código de Derecho Canónico y la promulgación del nuevo (1983), aún continúa la polémica acerca de si el matrimonio puede morir... Dentro de la iglesia católica algunos juristas han planteado la necesidad de revisar el canon 1060 ('favor juris') que favorece la institución antes que la persona humana ${ }^{3}$; ya en el Sínodo de Obispos (1980) algunos padres sinodales sugirieron igualmente la revisión de este canon ${ }^{4}$.

Por parte de los teólogos también ha habido mociones respecto de la posibilidad de reconocer, además de la muerte física de uno de los cónyuges y de la declaración de nulidad, otros motivos para la disolución del vínculo matrimonial; entre otros: B. Häring ${ }^{5}$, B. Petrà ${ }^{6}$, G. Cereti ${ }^{7}$, etc. La controversia en torno a la disolución del vínculo conyugal es aguda sólo

${ }^{1}$ Cfr. BenEDETTO XVI, "Il matrimonio non è una scelta impossibile". Discorso del Papa alla Rota Romana (29 Gennaio 2010), L'Osservatore Romano 30 Gennaio 2010, 7.

${ }^{2}$ Marco Ventura, "Quel bisogno di verità sull'inizio (e la fine) di un matrimonio", $I l$ Corriere della Sera 30 Gennaio 2010, 52. La traducción es mía.

${ }^{3}$ Cfr. Rufino CALle DE PAZ, "El 'favor matrimonii' (c. 1060): aspectos a revisar", CienciaTomista 127/1 (2000) 134-159; Bernardo VANEGAS, "La crítica actual del principio del 'favor matrimionii", Universitas Canónica 3 (1981) 313-341.

${ }^{4}$ Cfr. Giovanni CAPRILe, Il Sinodo dei Vescovi 1980, La Civiltà Cattolica, Roma 1982, 144, 1245, 146, 166, 180, 231, 296, 332, 341, 360, 364, 369, 373, 383, 468, 764, 771.

${ }^{5} \mathrm{Cfr}$. Bernard Häring, ¿Una vía sin salida?. Pastoral para divorciados, Herder, Barcelona 1990.

${ }^{6} \mathrm{Cfr}$. Basilio PETRÀ, Il matrimonio può morire?. Studi sulla pastorale dei divorziati risposati, EDB, Bologna 1996.

${ }^{7}$ Cfr. Giovanni CerETI, Matrimonio e indissolubilità. Nuove prospettive, EDB, Bologna 1971; IDEM, Divorziati risposati. Un nuovo inizio è possibile?, Cittadella, Assisi 2009. 
dentro de la iglesia católica, porque a nivel de la Iglesia Ortodoxa y de las Comunidades Protestantes el problema se plantea con relativa facilidad, con una notable flexibilidad.

La presente reflexión se propone ofrecer algunos planteamientos en torno al problema de la muerte del matrimonio, algunos datos de la historia de la iglesia en búsqueda de un camino hacia la solución y, finalmente, algunas perspectivas de futuro o propuestas de solución. Hay que tener presente que las posturas dentro de la iglesia católica se han radicalizado: el Magisterio se ha colocado en la línea dura de la firmeza en favor de la indisolubilidad absoluta del matrimonio 'rato y consumado', mientras que un grupo de teólogos y de laicos competentes plantean la posibilidad de una mitigación del rigor tradicional y se pronuncian en favor de una mayor apertura.

\section{Un conflicto difícil de resolver....}

Se trata de un problema espinoso por cuanto el Magisterio, a veces parece querer cerrar la puerta a cualquier intento de cambio en este campo. Testigo el pronunciamiento de Juan Pablo II según el cual "el matrimonio rato y consumado es intrínseca y extrínsecamente indisoluble. Es una enseñanza explícita y formalmente propuesta por el Magisterio, que debe considerarse como perteneciente a la doctrina católica, y como tal debe ser acogida y mantenida con firmeza"s.

El tema de la disolución del vínculo conyugal se convirtió en un tema, práticamente aceptado en el II Milenio, a partir de la formación de la legislación canónica cuando el derecho prevaleció sobre la reflexión teológica. Con la Escolástica se enfatizó la 'ontologización' de los sacramentos, se dio relieve a la institución y se reconoció más fuerza al acto humano en sí ('ex opere operato') que a la persona como sujeto de la acción ('ex opere operantis'). Pinckaers, queriendo interpretar al 'Doctor Angélico', ha reprochado el uso abusivo que se hizo de la expresión 'finis operis' y 'finis operantis', para dar el primado al objeto entendido en un sentido demasiado material y limitado?.

\footnotetext{
${ }^{8}$ Cfr. GIOVANNI PAOLO II, "Il matrimonio sacramentale rato e consumato non può mai essere sciolto neppure dalla potestà del Romano Pontefice", en Insegnamenti di Giovanni Paolo II, vol. XXIII/1 2000, Editrice Vaticana 2002, 101-108.

${ }^{9} \mathrm{Cfr}$. Servis PINCKAERS, Il rinnovamento della Morale. Studi per una morale fedele alle sue fonti e alla sua missione attuale, Borla, Torino 1968, 187; Pierre-Marie HOMBERT, "La formule 'ex opere operato' chez Saint Thomas”, Mélanges de Science Religieuse 49/3-4 (1992) 127-141.
} 
Es clara la inspiración jurídica que anima a los tratados teológicos del matrimonio; una inspiración que se condensa finalmente en la elaboración del viejo Código de Derecho Canónico (1917): el viejo Código de Derecho Canónico aparecía calcado sobre la estructura del derecho romano (normas generales, personas, cosas, delitos y penas). El tratado jurídico del matrimonio está insertado en el Libro III dedicado a 'las cosas'. De este modo los sacramentos quedan como 'cosificados'. Los elementos que configuran la doctrina canónica del matrimonio (contrato, consentimiento, impedimentos, efectos, débito conyugal, separación, revalidación) pertenecen netamente al campo jurídico.

A este respecto, el Concilio Vaticano II ha dado un giro de $180^{\circ}$ : "es la persona del hombre la que hay que salvar. Es la sociedad humana la que hay que renovar. Es, por consiguiente, el hombre; pero el hombre todo entero, cuerpo y alma, corazón y conciencia, inteligencia y voluntad..." (GS.3).

Pablo VI, cuando sugería las orientaciones a dar al nuevo código en la revisión propuesta por el Concilio Vaticano II (OT. 16), indicaba el espíritu de caridad, de moderación, de humanidad y de benignidad como características que deben tipificar el nuevo código; añadía una razón muy válida: porque las leyes de la iglesia deben diferenciarse de cualquier otro tipo de derecho humano y profano ${ }^{10}$. Un elemento novedoso en el nuevo Código de Derecho Canónico es el canon 1752 con que se cierra: establece este canon que la 'salus animarum' (la salvación de los hombres) "debe ser la ley suprema en la iglesia".

A veces se siente la tentación de pensar en ciertas incoherencias en el nuevo código si se tiene presente la insistencia del concilio en llevar a cabo la 'renovación' en los diversos estamentos de la iglesia. Por ejemplo, llama la atención que el canon $1055 \S 2$ establezca un cierto automatismo entre el contrato matrimonial de los bautizados y el sacramento; son varios los autores que cuestionan esta formulación ${ }^{11}$. Otro elemento a cuestionar es la presencia del 'favor juris' (c. 1060) en el nuevo código después de los reparos hechos en el Sínodo 1980 y la propuesta de revisión hecha por varios juristas.

${ }^{10}$ Cfr. Acta Commissionis, "Principia quae Codicis Juris Canonici recognitionem dirigant", Communicationes 1-2 (1969-70) 79.

${ }^{11}$ Cfr. Dionisio Borobio, "La sacramentalidad del matrimonio en relación con la experiencia actual”, Iglesia Viva 64-65 (1976) 391-419; John Baptist SEQUEIRA, Tout mariage entre baptisés est-il nécessairement sacramentel?. Etude historique, théologique e canonique sur le lien entre baptéme et mariage, Du Cerf, París 1985, 138-497; José M. LAHIDALGA, "En torno a la 'con-sistencia' del matrimonio sacramentalizado: una triple concepción", Lumen 26 (1977) 26-67. 
Llama igualmente la atención el hecho de la desaparición del canon $2214 \S 2$, presente en el viejo código pero que no tiene un canon correspondiente en el nuevo; se trata de una orientación eminentemente evangélica dirigida a los pastores de la iglesia en relación con el trato a dar a 'los súbditos': "que no se enseñoreen de ellos, sino que los amen como a hijos y hermanos". Valdría la pena trascribir todo el texto. Cuando se pregunta a los canonistas el por qué de esta desaparición, la respuesta es ésta: porque este canon no tenía estructura jurídica.

A este respecto es oportuno recordar la observación que hizo Benedicto XVI, dirigiéndose a la Rota Romana en la inauguración del Año Judicial 2006: el Papa ponía de relieve el contraste entre la sugerencia del Sínodo sobre la Eucaristía (2005) ${ }^{12}$, pidiendo estudiar la posibilidad de que los divorciados vueltos a casar puedan tener acceso a los sacramentos de la Penitencia y de la Eucaristía, y la Instrucción Dignitas connubii, del mismo año, que cierra la puerta a esta posibilidad. El Papa advertía que detrás de este contraste se esconde una pretendida contraposición entre derecho y la pastoral, como si la preocupación principal fuese la de ejecutar la formalidad jurídica prevista, con el riesgo de olvidar la finalidad pastoral del proceso ${ }^{13}$.

El conflicto es evidente: de una parte, se observa el hecho de los frecuentes fracasos matrimoniales; el divorcio aparece legitimado en los estatutos civiles de muchos países; muchos hombres y mujeres prefieren la 'unión consensual' antes que comprometerse con un matrimonio civil o eclesiástico; el 'compromiso provisorio' entra de lleno en las costumbres sociales. De otra parte, se constata que muchos tribunales eclesiásticos 'no funcionan bien', y que hace falta en los tribunales la participación de otros peritos, además de los canonistas; éste era el testimonio dado por J. Ratzinger cuando era Prefecto de la Congregación para la Doctrina de la Fe ${ }^{14}$.

Otro fenómeno, que urge atención por parte de la iglesia católica, es el de los 'matrimonios inter-confesionales' (matrimonios mixtos) que, al presente, se difunden ampliamente por diversos motivos (fusión de razas, de credos religiosos, de culturas, el turismo, la emigración, etc). Estas parejas

12 Cfr. Sinodo sull'EuCaristia, "Elenco finale delle Proposizioni", n. 40, Il Regno doc. 19 (2005) 553.

${ }^{13} \mathrm{Cfr}$. BENEDETTO XVI, "L'amore per la verità, fondamentale punto di incontro tra diritto e pastorale". Discorso in occasione dell'inaugurazione dell'Anno Giudiziario del Tribunale della Rota Romana, L'Osservatore Romano 29 Gennaio 2006, 5.

${ }^{14}$ Cfr. Joseph Ratzinger, "Introduzione" a la publicación de la obra de la CONGREGAZIONE PER LA DOTTRINA DELLA FEDE, Sulla pastorale dei divorziati risposati. Commenti e studi, Editrice Vaticana 1998, 25. 
inter-confesionales, en un momento de conflicto, encuentran por parte de las otras comunidades cristianas (Iglesia Ortodoxa y Comunidades Protestantes) una solución a su problema mediante una actitud benigna; no sucede lo mismo dentro de la iglesia católica que mantiene con firmeza el principio de la indisolubilidad del matrimonio.

Benedicto XVI, siendo Prefecto de la Congregación de la Doctrina de la Fe, en la 'Introducción' a la publicación de esta Congregación (Sulla pastorale dei divorziati risposati) llegó a afirmar que la "iglesia tiene el poder de señalar las condiciones que deben cumplirse para que un matrimonio pueda ser considerado como indisoluble según la enseñanza de Jesús"15. Esta sentencia puede entenderse como una señal de flexibilidad: el principio evangélico queda en pie, pero la interpretación para una justa aplicación podría reformarse.

\section{La historia de la Iglesia continúa "haciendo camino"}

Se podría afirmar que el II Milenio ha sido, en muchos aspectos, como un 'paréntesis' en la historia de la teología católica, porque la tradición de la iglesia primitiva se engancha mejor con la renovación impulsada por el Concilio Vaticano II.

W. Kasper ha afirmado que "apenas encontraremos en el Nuevo Testamento otra frase de Jesús que haya llegado hasta nosotros transmitida de modos tan variados como sucede con el caso de su pronunciamiento acerca de la imposibilidad del divorcio. Esto nos revela que desde el principio la iglesia no entendió la frase de Jesús a la manera de una párrafo legislativo, sino como palabra profética y mesiánica. Ya el evangelista Mateo añade a la disputa de Jesús $(19,1-9)$ una enseñanza dirigida a los discípulos $(19,10-12)$, considerada por la mayoría de los exegetas como tradición de la comunidad"16.

La iglesia primitiva, no obstante el rigor de un comienzo, acuñó un principio doctrinal y pastoral a la vez: 'la ley eminente' que proclama el principio evangélico de "no separar lo que Dios ha unido" y "la ley de la indulgencia', según la cual se atiende con misericordia la debilidad del hombre pecador ${ }^{17}$. Ese doble principio, fue puesto en boga por Orígenes, por varios Padres de la iglesia antigua, como S. Cipriano, S. Basilio, S. Juan Cri-

\footnotetext{
15 Joseph RATZINGER, "Introduzione" a la publicación de la obra de la CONGREGAZIONE PER LA DOTTRINA DELLA FEDE, Sulla pastorale dei divorziati risposati...., 25.

${ }^{16}$ Walter KASPER, Teología del matrimonio cristiano, Sal Terrae, Santander 1980, 72.

${ }^{17}$ Cfr. Charles Munier, "Le tómoignage d'Origène en matière de remariage après séparation", Revue de Droit Canonique 28 (1978) 15-29.
} 
sóstomo, S. Epifanio de Salamina ${ }^{18}$. Otro tanto hicieron algunos Pontífices Romanos (Gregorio I y Gregorio II) y algunos concilios regionales (Sínodo Romano, Concilio de Elvira, Concilio de Arlés $)^{19}$.

Muy posiblemente, el Cisma de Focio (1054), que operó la separación del Oriente de Occidente, causó también la ruptura con la tradición doctrinal del Oriente y, a partir de entonces la iglesia latina organizó su propia estructura sobre el derecho romano. Así se explica por qué hoy tengamos noticia de dos códigos que regulan a la iglesia latina y a la iglesia oriental. Ya se anotó anteriormente que la Iglesia Ortodoxa, en lo que respecta a los conflictos conyugales, ha conservado en buena parte, la tradición de la iglesia primitiva.

Un testimonio de cómo se comporta la Iglesia Ortodoxa ante el conflicto conyugal de separación y un nuevo matrimonio es el que dio E.Zoghbi, (Vicario Patriarcal para los Melquitas, en Egipto) durante una sesión conciliar; refiriéndose al cónyuge inocentemente abandonado, afirmó que la Iglesia Oriental siempre ha tenido conciencia de poseer autoridad para resolver los problemas de las parejas matrimoniales (con disolución del vínculo), y que esta tradición conservada en oriente y jamás reprobada podría ser adoptada en Occidente ${ }^{20}$.

El Sínodo de Obispos (1980) en las "43 Proposiciones" enviadas al Papa para la elaboración de la Exhortación Apostólica post-sinodal expresó el deseo de que la iglesia latina "movida por la solicitud pastoral hacia los fieles (divorciados) se proponga hacer una investigación cuidadosa, teniendo en cuenta la práctica de la iglesia oriental, con el objetivo de hacer más efectiva la misericordia pastoral" 21 .

En este Sínodo de Obispos muchos de ellos se pronunciaron en favor de una solución; Mons. A. Yeddanapally, Obispo indiano, aludía al hecho de que muchos de los divorciados muchas veces no se reconocen culpables del fracaso; de frente a este caso, la iglesia hace bien en subrayar la indisolubilidad del matrimonio, pero no puede descuidar a quienes se encuentran en tal situación ${ }^{22}$. Como esta, hubo muchas otras intervenciones.

18 Cfr. S. Cipriano, Epistula 55,29, en SAInT CYPRIAN, Letters (1-81), The catholic University of America Press, Washington 1964, 153; S. BASILIO, Lettera 188, PG. 32,677; S. Juan Crisóstomo, In Epist. ad Cor. Hom. 19, PG. 61,155; S. Epifanio DE SAlamina, Panarion 2,1. Haer. 59,4, PG. 41,1024.

19 Cfr. J. Silvio Botero G., La Fedeltà coniugale. Un problema d'attualità nella prospettiva del futuro, Vivere IN, Roma 2002, 48-55 y 56-58.

20 Cfr. Giovanni CAPRILe, Il Concilio Vaticano II. Quarto Periodo (1965), La Civiltà Cattolica, Roma 1969, 130-131.

21 SínOdo DEI VeSCOVI SUlla FAMIGLIA, "Le 43 proposizioni", Il Regno-Doc. 26 (1981) 390. La traducción es mía.

22 Cfr. Giovanni CAPRILE, Il Sinodo dei Vescovi 1980..., 180. 
Además de la preocupación de muchos obispos, son también muchos los teólogos que se han interesado en analizar el problema del fracaso en el matrimonio y su posible solución. Una explicación se puede encontrar en el cambio que el Cardenal Carter planteaba en el Sínodo de Obispos: tiempo atrás la conducta humana estaba guiada por principios 'a priori' que eran, como normas indiscutibles, puntos de referencia para distinguir el bien del mal, aunque no fueran tenidos en cuenta; pero hoy, especialmente entre los jóvenes, prima otro punto de vista: un principio 'a posteriori', es decir, es norma aceptar el dato social.

A este propósito, se preguntaba si acaso el Espíritu Sto. no está hablando a la iglesia desde esta coyuntura... Este signo de los tiempos, que podría llamarse 'pos-tradicional', no será una expresión de lo que hoy se está designando como 'sensus fidelium'?. De todas formas, la iglesia no puede ignorar la situación social contemporánea, sea que se la considere como voz del Espíritu, sea que revele una señal de la desmoralización, de la decadencia moral de nuestro tiempo ${ }^{23}$.

Por parte de los teólogos y de los canonistas en actitud de apertura surge una serie de interpelaciones a la forma tradicional de proceder de la iglesia en el caso del fracaso matrimonial: el matrimonio nace, pero también puede morir... Algunas de estas interpelaciones son éstas:

- J. Günter Gerhartz se pregunta “ ¿si tal vez la iglesia tiene el poder de disolver todos los matrimonios, pero aún no se ha enterado de ello?. O bien, ¿la única razón válida de la iglesia para rechazar la disolución del matrimonio sacramental consumado es que no quiere hacerlo? (...) ¿Es cierto, y se podría demostrar que en el futuro la iglesia continuará transfiriendo al nivel jurídico -en la forma practicada desde el siglo XII, es decir, como una exigencia de indisolubilidad jurídica sin ninguna excepción- la exigencia moral absoluta de indisolubilidad que Jesús señala a todo matrimonio?"24.

$\mathrm{El}$ autor responde rebatiendo una posible salida: "el argumento 'facit, ergo postest' (lo hace, luego puede), 'non facit, ergo non potest' (no lo hace, luego no puede) - tan adornado, como se quiera con razones teológicas y con el recurso a la voluntad de Dios- sigue siendo en todo caso poco convincente. (...) En el pasado, esta concepción en la que Dios es considerado

\footnotetext{
${ }^{23}$ Cfr. Giovanni CAPRILE, Il Sinodo dei Vescovi $1980 . . ., 130-131$

24 Johannes GÜNTER GERHARTZ, "La indisolubilidad del matrimonio y su disolución por la iglesia en la problemática actual", en Matrimonio y divorcio, Sígueme, Salamanca 1974, $225-226$.
} 
como legislador humano y en la que se le hace actuar como tal, ha podido parecer satisfactoria . Hoy día, más bien constituye una invitación a buscar más lejos. ¿Se puede realmente aducir una razón convincente que explique por qué sólo el matrimonio sacramental y como tal consumado es , jurídicamente hablando, absolutamente indisoluble?"25.

- Tradicionalmente la iglesia ha urgido a los divorciados reconciliarse, o no volver a casarse, y si lo hicieren deberán 'vivir como hermano y hermana'. Mons. E. Zoghbi, citado anteriormente, objetaba durante el concilio esta medida: permanecer solo y conservar la castidad por el resto de la vida es una solución que supone virtud heroica y una fe poco común; el heroísmo y el estado de perfección jamás han sido impuestos so pena de condenación. No parece normal que la continencia perpetua como estado de perfección pueda ser impuesta como una obligación, casi como un castigo, al cónyuge inocente ${ }^{26}$.

Realmente no parece justo que a una persona, cuya vocación es el matrimonio, se le imponga otro tipo de vida para el cual no fue creada. En la iglesia primitiva un criterio para autorizar al divorciado un nuevo matrimonio era la imposibilidad de mantenerse continente, máxime si esta persona era todavía joven. Si la reconciliación se hace imposible y la persona no puede conservar la continencia, exigirle mantenerse célibe es colocarla en una situación de riesgo de contraer una unión ilegítima, o entrar en un estado de angustia de conciencia a causa del peligro de condenación. Así veía esta situación Mons. Zoghbi.

- Un argumento que se está ventilando en el postconcilio parte del amor conyugal como fundamento de la indisolubilidad. H. Cohen solía definir el matrimonio como 'el amor que se hace fiel'27. Pero han sido sobre todo el Concilio Vaticano II y el Magisterio de Juan Pablo II quienes han considerado el matrimonio como el 'sacramento del amor'. No fue fácil llegar a esta conclusión; a ella precedió una larga discusión entre teólogos y canonistas ${ }^{28}$.

25 Johannes GÜNTER GERHARTZ, "La indisolubilidad del matrimonio y su disolución por la iglesia en la problemática actual"..., 226 y 230.

${ }^{26}$ Cfr. Giovanni CAPrile, Il Concilio Vaticano II. Quarto Periodo (1965)..., 130-131; J. Silvio BoTERo G., "Vocación matrimonial y continencia perpetua por mandato?. La situación del cónyuge abandonado", Religión y Cultura 54/247 (2008) 881-906.

27 Cfr. Herman CoHEN, System der Philosophie. Etik des reinen Willens, B. Cassirer, Berlín 1921, 587: "Die Begründung der Liebe in der Treue ist die Ehe".

${ }^{28}$ Cfr. Vincenzo Fagrolo, Editore, L'amore coniugale, Città del Vaticano 1971; Giuseppe BALDANZA, "In che senso ed entro quali limiti si puo parlare di una rilevanza giuridica dell'amore coniugale dopo la Costituzione Pastorale Gaudium et Spes", La Scuola Cattolica 96 (1968) 43-66. 
En un principio, los canonistas se negaban a admitir que el amor conyugal posea una dimensión jurídica; en el Tribunal de la Rota Romana cursaban varias causas de demanda contra el vínculo matrimonial por ausencia del amor conyugal en una determinada pareja ${ }^{29}$. Al presente, la situación es ésta: si al momento de celebrar la boda no había amor esponsal genuino entre los contrayentes, no hubo matrimonio; esta tesis fue demostrada por V. Fagiolo, juez rotal en $1970^{30}$.

Queda en plan de estudio el caso en que el amor 'venga a menos' o llegue a desaparecer totalmente después de celebrado el matrimonio. No faltan argumentos para llevar adelante esta nueva tesis: ¿si el amor conyugal no existe ya, en qué echa raíces la sacramentalidad del matrimonio?. No en vano se afirma que el matrimonio es el sacramento del amor.

- Una interpelación que no ha sido lo bastante difundida es ésta: cuando uno de los cónyuges niega sin motivo, en forma unilateral y continua, la relación conyugal al consorte, tiene sentido afirmar que la donación recíproca y total a nivel sexual entre los esposos es signo de la alianza esponsal? El viejo Código de Derecho Canónico (c. 1081 § 2) alude al 'jus in corpus perpetuum et exclusivum') y el nuevo Código (c. 1061) hace referencia al "acto conyugal (...) mediante el cual los cónyuges se hacen una sola carne". Esto revela la continuidad en la legislación canónica acerca del relieve jurídico que se reconoce a la relación conyugal.

Igualmente la Gaudium et spes subraya la importancia de esta relación: "con la unión íntima de sus personas y actividades se ayudan y se sostienen mutuamente, adquieren conciencia de su unidad y la logran cada vez más plenamente. Esta íntima unión, como mutua entrega de dos personas, lo mismo que el bien de los hijos, exigen plena fidelidad conyugal y urgen su indisoluble unidad" (48).

Piero A. Bonnet, comentando el c. 1057 § 2 del nuevo código, encuentra en el relato del Génesis (2,21-24) la razón de la atracción recíproca de los dos sexos: "los vocablos hebreos 'ish' e 'ishah' provienen probablemente de una misma raíz 'enos' que expresa la esencia de una cosa. De este modo el autor sagrado ha querido mostrar cómo el hombre y la mujer constituyen una unidad profunda" 31 .

${ }^{29} \mathrm{Cfr}$. Diego De CARO, "La Comunicazione interpersonale e l'amore coniugale nel matrimonio canónico", Monitor Ecclesiasticus 110 (1985) 511-531; Santiago Panizo Orallo, "Las sentencias rotales del año 1970", Revista Española de Derecho Canónico 37 (1981) 467-506.

${ }^{30}$ Cfr. Vincenzo Fagiolo, "Chicagien. Nullitatis matrimonii", en Sacrae Romanae Rotae Decisiones seu sententiae 62 (1972) 978-990.

${ }^{31}$ Piero Antonio BoNNET, "Il consenso matrimoniale", en Matrimonio canonico fra tradizione e rinnovamento, EDB, Bologna, 1991, 165. La traducción es mía; IDEM, "Il princi- 
Son varios los autores (Juan Pablo II, B. Häring, W. Kasper, G. Gatti, B. Petrà) que, al querer definir el matrimonio, hacen una 'tríada' inseparable con estos tres términos: amor - sexualidad - sacramento: se trata del amor esponsal que se expresa a través del gesto sexual para constituir la realidad sacramental ${ }^{32}$. Por tanto, la negación arbitraria, unilateral, de la relación conyugal implica la negación del derecho a constituir con el otro la unidad del 'una sola carne'. Un tal rechazo falsea en su misma raíz la esencia del matrimonio porque prescinde de un elemento fundamental en la constitución del matrimonio.

Estas diversas interpelaciones piden que, además de las causas de nulidad que el estatuto canónico tiene establecidas (muerte del cónyuge, declaración de nulidad y las causales de nulidad más recientemente admitidas por la Rota Romana) se estudien con seriedad los nuevos motivos que surgen. Mantener a toda costa la afirmación de que el matrimonio 'rato y consumado es absoluamente indisoluble' no parece plenamente razonable. El relieve a dar a la persona humana sobre la institución es una voz que se alza desde muchos puntos convergentes de estudio de la realidad matrimonial.El matrimonio es para el hombre, no el hombre para el matrimonio.

\section{Algunas perspectivas de solución}

Prácticamente hasta el Concilio Vaticano II, si se observa la publicación periódica de las sentencias de la Rota Romana, se advierte que las únicas causales de nulidad matrimonial eran la exclusión de uno o de varios de los 'tria bona coniugalia', propuestos por S. Agustín: 'bonum prolis', 'bonum fidei', 'bonum sacramenti' ${ }^{33}$. Con posterioridad al Vaticano II se constata con claridad que la demanda de nulidad por la exclusión de uno de los 'tres bienes' del matrimonio no es tan frecuente; en cambio, se insinúan cada vez más nuevas causales de nulidad como son, por ejemplo, la incapacidad para asumir las obligaciones esenciales del matrimonio, el defecto de discreción de juicio, el miedo o la fuerza, la simulación ${ }^{34}$.

A estas causales ya canonizadas por la Rota Romana se podrían añadir algunas propuestas que van apareciendo entre los teólogos y juristas

pio di indissolubilità nel matrimonio quale stato di vita tra i battezzati”, en Studi sul matrimonio canonico, a cura di Pio Fedele, Catholic Book Agency, Roma 1982, 182-218.

${ }^{32}$ Cfr. J. Silvio Botero G., Una nuova morale matrimoniale, Logos, Roma 2007, 38-39.

${ }^{33}$ Cfr. S. Agustinus, "De Genesi ad litteram", en PL. 34,397; Pedro LANGA, "La fórmula 'proles, fides, sacramentum", Religión y Cultura 117 (1980) 357-388.

${ }^{34}$ Cfr. Rotae Romanae Tribunal, Decisiones seu sententiae 92 (2000). 
con el objetivo de iluminar posibles pistas de solución que sugieren la aceptación de que el matrimonio puede morir y, por tanto, la posibilidad de un nuevo matrimonio. A continuación se plantean algunas de estas propuestas.

- Lahidalga había propuesto un doble planteamiento: "los tribunales eclesiásticos se limitarían a 'constatar' o 'declarar' que contra lo que se creía o parecía, no hubo desde el primer momento ('ex tunc') matrimonio alguno. Estas son las clásicas 'anulaciones' o sentencias de nulidad' que dicta la iglesia"35.

Una hipótesis de estudio que conlleva novedad es ésta: "cuando se trata de matrimonios cristianos que fueron válidos desde el principio, pero que después, tras cierto tiempo -incluso años- se deterioran y fracasan sin remedio, pensamos que cabría no una disolución sino una mera declaración de nulidad 'ex nunc', esto es, desde el momento, posterior a su válida celebración, en que se constata su fracaso irremediable. Evidentemente, queremos considerar no el matrimonio con problemas o el matrimonio que pasa por momentos conflictivos, que puede tener y muchas veces tiene remedio. Nos ponemos en el caso más extremo: el matrimonio irremediablemente fracasado o roto"36.

Juan Pablo II, en la Familiaris consortio admite la posibilidad de un matrimonio 'irreparablemente destruido': "finalmente están los que han contraído una segunda unión en vista a la educación de los hijos, y a veces están subjetivamente seguros en conciencia de que el precedente matrimonio, irreparablemente destruido, no había sido nunca válido"(84). El Papa no sugiere qué se puede hacer en este caso, pero deja planteada una situación que merece consideración.

- J. Bernhard ha propuesto una tesis en vista a superar la concepción tradicional del matrimonio 'rato y consumado' que es indisoluble según el canon 1141. Este canonista propone una nueva formulación que designa como 'consumación existencial y en la fe'; según esta perspectiva, alude al 'matrimonio instaurado' y al 'matrimonio consagrado'. 'Matrimonio instaurado' será aquel que resulta del intercambio de consentimientos a un matrimonio intrínsecamente y fundamentalmente indisoluble en que los esposos prometen hacer todo lo posible de su parte para progresar hacia un matrimonio indisoluble (intrínseca y extrínsecamente)"37.

35 José M. LAHIDALGA, "La 'declaración de nulidad y el matrimonio cristiano: una sugerencia pastoral", Lumen 543-544 (1993) 47.

36 José M. LAHIDALGA, "La 'declaración de nulidad y el matrimonio cristiano....", 48.

${ }^{37}$ Jean BERNHARD, "Reinterpretación (existencial y en la fe) de la legislación canónica concerniente a la indisolubilidad del matrimonio cristiano", en Divorcio e indisolubilidad del matrimonio, Herder, Barcelona 1974, 50. 
'Matrimonio consagrado' será, en cambio, aquel en que "los esposos llegan a un cierto perfeccionamiento humano y cristiano que constituye una comunidad de vida y de amor, símbolo explícito de la unión de Cristo con su iglesia"38. La Gaudium et spes hace referencia repetidas veces a este perfeccionamiento: "los esposos cristianos (...) están como consagrados por un sacramento especial (...) que satura toda su vida de fe, esperanza y caridad, llegan cada vez más a su propia perfección y a su mutua santificación..." (48).

Es J. Bernhard quien indica los signos de que esta 'consumación existencial' no se ha cumplido: brevedad de la vida en común, infidelidad desde el comienzo de la vida conyugal, ausencia de todo testimonio conyugal humano y cristiano, dificultad para establecer una relación auténtica, intolerancia en la vida común, un matrimonio definitivamente roto.

J. Bernhard no es el único a plantear este tipo de consumación; con él hay otro autores que comparten esta idea: D.J. Doherty, M. J. Curran, E. Hudson $^{39}$. A este propósito, G. Montini ha hecho una reflexión sugestiva, gráfica, para explicar la razón de que la consumación del matrimonio no es obra de la primera relación conyugal solamente: 'el matrimonio no se hace en una noche'40. El principio ético de la 'gradualidad' propuesto por el Sínodo de Obispos (1980) y reconfirmado por Juan Pablo II en la Familiaris consortio (34) es otro punto de apoyo a la tesis de la 'consumación existencial' del matrimonio, además de los que propone J. Bernhard.

- Una posible alternativa a los problemas que afectan al vínculo conyugal es la llamada solución de 'buena conciencia' propuesta en 1972 por el Obispo de Baton Rouge (Lousiana-USA): "en algunos casos en los cuales los casados en segundas nupcias no han podido obtener la declaración de nulidad o el divorcio de su primer matrimonio (...) se les considera vivir en buena conciencia si están realmente convencidos de que el primer matrimonio de uno de ellos o de los dos no era un verdadero matrimonio" 41 .

38 Jean BERNHARD, "Reinterpretación (existencial y en la fe)...“, 51.

${ }^{39} \mathrm{Cfr}$. Dennis J. DoherTY, Divorce and Marriage. Resolving a catholic Dilemma, Abbey Press St. Meinrad, Indiana 1974, 67-84; M. J. CURRAN, Conjugal consummation in the catholic Church, Pontificia Università Lateranense, Roma 1988, 383-422; E. Hudson, "Marital Consummation. According to ecclesiastical Legislation", Studia Canonica 122 (1978) 93-123.

${ }^{40} \mathrm{Cfr}$. Gianpaolo MONTINI, "Una coppia non si fa in una notte. Alcune riflessioni sul concetto di consumazione del matrimonio", en Il matrimonio, Quaderni Teologici del Seminario di Brescia, Morcelliana, Brescia 1999, 175-212.

${ }^{41}$ Stephen J. KelleHER, ¿Divorcio y nuevo matrimonio entre católicos?, Sal Terrae, Santander 1976, 163 . 
Fue una práctica que desde 1945 estaba en uso en la Arquidiócesis de Chicago, difundida incluso en otras diócesis norteamericanas, pero prohibida en 1972 por la Sta. Sede.

Un poco antes se ha hecho alusión a la Familiaris consortio en la que el Papa hacía referencia a la posibilidad de que algunos esposos "a veces están subjetivamente seguros en conciencia de que el precedente matrimonio, irreparablemente destruido, no había sido nunca válido" (84), pero no adelantaba ninguna posible solución.

La propuesta de solución de 'buena conciencia' no ha desaparecido; en 1998, Ratzinger, introduciendo la publicación de la Carta a los Obispos acerca de la pastoral de los divorciados vueltos a casar, recogía las dos opiniones en torno al uso de la epiqueya en el 'fuero interno': algunos afirman que en el 'fuero interno' los fieles deben atenerse absolutamente al juicio del tribunal aunque les parezca falso el dictamen; otros, en cambio, opinan que es posible alguna excepción porque en el ordenamiento procesal no se trata del derecho divino sino del derecho eclesial. Ratzinger creía que en línea de principio no parece que se excluya la aplicación de la epiqueya en el fuero interno ${ }^{42}$.

En el año 2003 T. Vanzetto, después de analizar tres posibles situaciones en que puede encontrarse un tribunal eclesiástico respecto a cuestiones de nulidad matrimonial, propone una alternativa: "si aún la certeza de nulidad, en la conciencia del fiel fuera verdaderamente objetiva y no se pudiese demostrar este matrimonio en cuanto nulo, no constituye un impedimento de vínculo para un nuevo matrimonio, aunque la celebración sea ilícita según el derecho positivo" 43 .

Otros estudiosos del problema como G. Russo y P. Bianchi han analizado el problema pastoral que se plantea entre un matrimonio nulo y el conflicto de conciencia. Para Russo es importante tener presente que hoy con el relieve que el Concilio Vaticano ha dado a la conciencia ética de la persona humana, el aspecto jurídico que, en el pre-concilio era dominante, ahora cede el paso a la dimensión de la persona; de este modo se opera un cambio de paradigma a partir de una nueva concepción del hombre. Esta nueva perspectiva está generando una cierta discrepancia insoluble entre el estado de la vida legal y el estado real de la pareja humana. La tradición

\footnotetext{
${ }^{42}$ Cfr. Joseph Ratzinger, "Introduzione" a la publicación de la obra de la CoNGreGAZIONE PER LA DOTTRINA DELLA FEDE, Sulla pastorale dei divorziati risposati....., 26.

43 Tiziano VANZETTO, "La via del tribunale ecclesiastico e la coscienza della nullità", Credereoggi 23/4/136 (2003) 123.
} 
pre-conciliar había acentuado excesivamente el 'tuciorismo' (buscando la mayor garantía jurídica posible a la institución $)^{44}$.

P. Bianchi, concluyendo la reflexión que hace acerca de 'la nulidad del matrimonio no demostrable', afirma que no es un problema pastoral general, que el ordenamiento jurídico se esfuerza por dar cabida a la equidad canónica huyendo de los formalismos, y que en los casos de conflicto se puede recurrir a los principios clásicos de la moral; entre otros, enuncia el hecho de que tratándose de una ley meramente eclesiástica, y de que el derecho al matrimonio es un bien tan importante para la persona humana, pueden darse circunstancias en las que es lícita la celebración del segundo matrimonio, si de la privación de éste se siguen consecuencias graves, no se da ocasión de escándalo y no se prevé algún conflicto práctico entre éste y el primer matrimonio ${ }^{45}$.

- La teología y también el derecho canónico recurren frecuentemente a la 'analogía' para establecer un cierto paralelo entre algunas categorías que en alguna forma se asemejan, pero que también se diferencian. Es posible descubrir diversas analogías entre el matrimonio y otra categorías teológicas ${ }^{46}$. Una de estas analogías es el paralelo que S. Roberto Belarmino estableció entre la Eucaristía y el Matrimonio.

Afirma el 'Belarmino' que el matrimonio es sacramento, como la Eucaristía, de dos modos: mientras se confecciona ('dum fit') y en su duración ('dum permanet'); por esta razón ambos sacramentos se asemejan ${ }^{47}$. La Eucaristía y el Matrimonio se hacen mediante la fórmula consacratoria ("esto es mi cuerpo...", "yo me entrego a ti') y subsisten mientras las especies sobrevivan (el pan y el vino, uno u otro de los contrayentes).

S. Roberto Belarmino se limitó a proponer la analogía, pero no dedujo las consecuencias que de ella se pueden derivar. Pío XI en la encíclica Casti connubii (1930) y Juan Pablo II en la Familiaris consortio (n. 57) y en el Congreso Eucarístico de Nairobi (15 Agosto 1984) aludieron a esta analogía pero sin deducir consecuencias en orden a la cesación del sacramento.

\footnotetext{
${ }^{44}$ Cfr. Giovanni Russo, "Matrimonio nullo e conflitto di coscienza. Considerazioni etiche a partire dalla normativa canonica", Apollinaris 65/1-2 (1992) 329-350.

${ }^{45}$ Cfr. Paolo BIANCHI, "Nullità di matrimonio non dimostrabili. Equivoco o problema pastorale?", Quaderni di Diritto Ecclesiale 6/3 (1993) 280-297.

${ }^{46}$ Cfr. J. Silvio Botero G., La fedelta coniugale. Un problema d'attualità nella prospettiva del futuro, Vivere In, Roma 2002, 204-238.

${ }^{47}$ Cfr. Roberti Bellarmini, De controversiis christianae fidei, vol. III, Venetiis 1721, "De sacramento matrimonii', controversia II, cap. VI, n. 628.
} 
Anteriormente Sto. Tomás De Aquino en el Comentario a los Cuatro Libros de las Sentencias de P. Lombardo se había referido en alguna manera a esta misma analogía: el 'Doctor Angélico' afirmaba que de dos maneras puede dejar de existir una relación: porque deja de existir uno de los términos de la relación ('ex corruptione subiecti') o porque desaparece lo que constituye la relación ('ex subtractione causae') ${ }^{48}$.

Esta analogía entre Eucaristía y Matrimonio ha sido objeto de estudio por parte de muchos teólogos ${ }^{49}$. Estos autores, en general, subrayan en la analogía los elementos de banquete de comunión, de alianza, de entrega recíproca, de identificación entre Anfitrión y comida, etc, pero no hacen aplicación de la cesación de la Eucaristía a las posibles formas de cesación del matrimonio. No se podría afirmar que la analogía entre Eucaristía y Matrimonio se queda a mitad de camino en la reflexión, que se hace una aplicación sólo parcial? ${ }^{50}$.

Aplicando la analogía a la forma de cesación de la Eucaristía al 'venir a menos' el matrimonio, la teología católica asume sólo parcialmente la forma como el 'Doctor Angélico' explica la cesación de una relación: por muerte de uno de los cónyuges ('ex corruptione subiecti') y la desaparición del constitutivo de la relación ('ex subtractione causae'). En el caso presente la desaparición del fundamento de la relación en el matrimonio podría ser porque muere el amor conyugal en forma irremediable, porque se niega arbitraria, unilateralmente y en forma duradera la entrega recíproca, total, exclusiva de las personas.

- Sin querer sex exhaustivos en este elenco de perspectivas de solución, conviene enunciar una más: se trata de una posible causa de disolución del matrimonio 'rato y consumado' en virtud de un 'motivo superior'; es el planteamiento que hace A. Carrillo A. en su tesis de doctorado en derecho canónico en la Universidad de Comillas-Madrid (1976).

${ }^{48}$ Cfr. S. Thomae Aquinatis, Scriptum super Libros Sententiarum Magister Petri Lombardi, Editio Nova, a cura di P. Mandonnet, Lethielleux, Parisiis 1929, Distinctio 41, q. 1, a. 1., solutio $2^{\mathrm{a}}$.

${ }^{49}$ Cfr. Marc Ouellet, "Eucharistie, cadeau nuptial", Communio 25/3 (2000) 19-40; Bernhard FRANCK, "L'Eucharistie: veritable sceau du mariage", Revue de Droit Canonique 31/3-4 (1981) 171-188; Michel M. HERBST, "The Eucharistic, Meaning of Marriage", Anthropotes 2 (1994) 161-176; Francesco MARINELLI, "Eucaristia e Matrimonio", Lateranum 56 (1990) 117-142; J. Silvio Botero G., "Eucaristía y Matrimonio, fundamento de una relación", Studia Moralia 35 (1997) 375-400.

50 J. Silvio Botero G., "Eucaristía y Matrimonio: una aplicación de la analogía sólo parcial?", Studium 47 (2007) 409-424. 
El 'motivo superior' a que se refiere es "la unidad en la fe católica como personas, un motivo superior prevalente a la permanencia de aquel vínculo, incompatible por otra parte, para salvar la fe católica de estas personas, cuando prácticamente no hay otra solución. Máxime cuando se da la buena fe en esas personas, porque su situación anormal es fruto de la practica seguida en su iglesia o secta. Sería cerrar la puerta a la unidad, pues, prácticamente, es imposible un retorno al primer matrimonio y un abandono de la segunda unión" 51 .

En sí misma esta perspectiva no es nueva: ya el Apóstol Pablo la sugirió en su Primera Carta a los Corintios (7,12-15): se refiere al caso en que "la parte no creyente quiere separarse del creyente..."; "que se separe.(...) pues, a vivir en paz los llamó el Señor". Es el llamado 'Privilegio paulino' aceptado plenamente en la iglesia (canon $1143 \S 1)^{52}$.

Entre los Padres de la iglesia primitiva, S. Juan Crisóstomo es explícito a este respecto: en el comentario a la Carta a los Corintios (Homilía $19^{\mathrm{a}}$ ) plantea el caso del infiel que ordena al cónyuge venerar la divinidad pagana o hacerse cómplice con él en la impiedad, o de lo contrario lo amenaza con separarse de él; en este caso, afirma el Crisóstomo "es preferible romper el vínculo matrimonial antes que ofender la religión" ("melius est disrumpi connubium quam piam religionem') ${ }^{53}$.

Tanto el viejo Código de Derecho Canónico (canon 1124) como el nuevo (canon $1143 \$ 2$ ) aluden a la posibilidad de cohabitar pacíficamente sin ofensa del Creador' ('sine contumelia Creatoris'). Con el 'privilegio paulino' se pretende defender la fe y la serenidad de la parte bautizada, garantizándole una vida pacífica y evitándole el peligro de una posible perversión, escribe Chiappetta ${ }^{54}$.

Carrillo intenta ir más allá del 'privilegio paulino'; afirma que "el principio que quiere salvar S. Pablo es aplicable a todo cristiano, en cuanto persona cristiana y no sólo en cuanto esposo. No puede dudarse de que este peligro de perder la fe y la paz cristiana puede existir incluso cuando ambos son cristianos, sin que sea suficiente para salvarlo la sola separación sin la

${ }^{51}$ Alfonso Carrillo Agullar, Disolución del vínculo y potestad de la iglesia. ¿Puede la iglesia disolver el matrimonio sacramental consumado?, Córdoba 1976, 295.

52 Cfr. Benedetto Prete, Matrimonio e continenza nel cristianesimo delle origini, Paideia, Brescia 1979, 133-160; Luigi CHIAPPETTA, Il matrimonio nella nuova legislazione canonica e concordataria. Manuale giuridico-pastorale, Dehoniane, Roma 1990, 369-375.

${ }^{53}$ Cfr. S. JoAnnis Chrysostomi, In Epistula I. ad Corinthios, Hom. XIX, PG. 57, 155.

$54 \mathrm{Cfr}$. Luigi CHIAPPETTA, Il matrimonio nella nuova legislazione canonica e concordataria..., 372, n. 1086. 
solución y la posibilidad de nuevas nupcias. Piénsese, por ejemplo, en casos realísimos en que existe peligro de incontinencia. En tales casos, según $\mathrm{S}$. Pablo, 'mejor es casarse que quemarse' (I. Cor. 7,9). Para S. Pablo lo que fundamenta la posibilidad o no de disolución, no es la naturaleza del vínculo tipificado ${ }^{55}$.

No se podría tomar pie a este propósito, el texto de S. Mateo en relación con la corrección fraterna cuando afirma que "si desoye hasta la misma comunidad, sea para tí como el gentil y el publicano"(18,17)?. J. Gnilka, comentando esta sentencia del evangelista, afirma que la fórmula 'considéresele como gentil y publicano' hace pensar que prácticamente la comunidad cesaba todo tipo de relación con él ${ }^{56}$.

Las anteriores perspectivas de futuro en torno a la posible disolución del matrimonio 'rato y consumado' están indicando sutilmente que algo se mueve en favor de una mayor flexibilidad; en la reflexión del II Milenio sobre el matrimonio es posible detectar una cierta 'fijación'57 del pensamiento teológico dejándose influir por la legislación canónica; esta 'fijación' contrasta con lo que afirma W. Kasper: "la iglesia post-pascual hubo de elaborar constantemente, con la ayuda del espíritu de Jesús que le había sido otorgado, nuevos ordenamientos en los que, por una parte, se salvaguardase en toda su plenitud la exigencia escatológica de Jesús y, por otra, se tuviese en cuenta la situación concreta. La iglesia percibió sin duda, desde el comienzo y como cosa suya, esta tarea"58.

En otro momento de la presente reflexión se ha afirmado que la iglesia parece querer mantener la continuidad con la iglesia primitiva en la práctica sacramental a partir de la segunda mitad del siglo $\mathrm{XX}$, porque el II Milenio parece más bien como un paréntesis por causa de una cierta fijación en lo doctrinal. Ha sido, sobre todo, el Concilio Vaticano II el que ha impulsado una auténtica 'renovación' dentro de la teología (OT. 16); no sólo a nivel general, sino muy especialmente en torno a la teología del matrimonio: dando relieve al amor conyugal como esencia del matrimonio, la revaloración de la sexualidad humana, una nueva óptica con relación a la sacramentalidad, entre otros aspectos ${ }^{59}$ :

\footnotetext{
55 Alfonso Carrillo Agullar, Disolución del vínculo y potestad de la iglesia......, 292.

${ }^{56}$ Cfr. Joachim GnILKA, Il Vangelo di Matteo. Commentario teologico del Nuovo Testamento, II Parte, Paideia, Brescia 1991, 207.

57 Cfr. Philippe DelHAYE, "Fissazione dogmatica della teologia medioevale Sacramento, vincolo, rato e consumato", Concilium 6/5 (1970) 106-112.

58 Walter KASPER, Teología del matrimonio cristiano....., 72.

${ }^{59}$ Cfr. J. Silvio Botero G., Una nueva morale matrimoniale, Logos, Roma 2007, 39-154.
} 
El amor conyugal, que se expresa mediante la entrega recíproca, total y exclusiva de sus personas, se convierte en el sacramento ('símbolo') de la alianza de Cristo con la iglesia; ¿si el amor conyugal llegase a desaparecer, llegase a morir y con él también el sentido de la entrega sexual, sobre qué base se puede fundar la dimensión sacramental? ¿Sobre la base del contrato matrimonial, indisoluble, irreversible? Ésta es una ficción jurídica.

G. Cereti ha afirmado que una vez destruido el amor conyugal y cuando viene a menos la voluntad de los dos esposos de continuar viviendo como marido y mujer, por culpa de uno o de ambos, sería blasfemo pensar que un signo inexistente ya pueda todavía ser símbolo del amor de Dios por la humanidad; nadie sobre la tierra ha autorizado destruir aquel signo sacramental que subsiste en el amor de los esposos y en la voluntad de ser marido y mujer; nadie tampoco tiene el poder de hacer sobrevivir un signo de que vino a menos la voluntad de ser más marido y mujer ${ }^{60}$.

Ya en el Sínodo de Obispos sobre la familia (1980) Mons. H. Légaré proponía el paso de una 'filosofía esencialista', según la cual se pensaba que la iglesia se halla en estado de perfección, a una 'filosofía existencialista y personalista' que toma en cuenta la realidad como se va presentando históricamente ${ }^{61}$. No se puede hacer una analogía matemática entre la fidelidad de Cristo a la iglesia y la fidelidad de los esposos: la primera es absoluta, indefectible; la segunda está marcada por la fragilidad humana. El mismo S. Agustín admitía que la relación 'Cristo-Iglesia' debe designarse como 'sacramentum magnum' mientras que a la relación conyugal entre varónmujer debe llamársele 'sacramentum minimum'62.

En esta línea de distinguir el 'primer analogado' (Cristo-Iglesia) del 'segundo analogado' (hombre-mujer casados) el diálogo ecuménico ha logrado acercar a las iglesias cristianas en favor de un mejor entendimiento sobre la indisolubilidad del matrimonio que progresivamente se va abriendo camino: las iglesias, afirma Cereti, sostienen conjuntamente que, el matrimonio fundado sobre el amor en cuanto tal es símbolo del amor de Dios en la alianza; las divergencias se presentan a nivel pastoral.

Un acuerdo hecho entre la Federación Luterana Mundial y el Pontificio Consejo para la Unidad de los Cristianos reconoce que en las Iglesias

${ }^{60} \mathrm{Cfr}$. Giovanni CERETI, Divorziati risposati. Un nuovo inizio è possibile?. Cittadella, Assisi, 2009, 105 .

${ }^{61}$ Cfr. Giovanni CAPRILE, Il Sinodo dei Vescovi 1980..., 124.

${ }^{62}$ Cfr. S. Augustinus, De nuptiis et concupiscentia 1,21 PL. 44,425; Emille SCHMrTT, "Le 'sacramentum' dans la théologie augustienne du mariage. Analyse sémantique", Revue de Droit Canonique 42/2 (1992) 197-213. 
de la Reforma se proclama una fidelidad conyugal que se concilia con la esperanza, de que en caso de fracaso, un nuevo matrimonio pueda realizar aquella unidad que, según el designio de Dios, no logró conseguir el primer matrimonio $^{63}$.

\section{Conclusiones}

La reflexión hecha sobre "El matrimonio nace... el matrimonio muere...Dos posiciones de cara al fracaso conyugal" es un tema que, si bien el Magisterio de la Iglesia ha intentado darlo por cerrado, sin embargo algunos teólogos y juristas lo han continuado, sin que esto les haya ocasionado algún reproche por parte del Magisterio ${ }^{64}$.

Entrando a hacer la conclusión a esta reflexión, surgen varios puntos a destacar, teniendo en cuenta la evolución homogénea del dogma en lo que se refiere al sacramento del matrimonio.

- En primer lugar, se debe subrayar la continuidad que se observa entre la actitud pastoral de la iglesia primitiva y la reflexión teológico-pastoral que se viene haciendo, prácticamente, desde la II Mitad del siglo XX: se mantiene en pie el principio evangélico de que "el hombre no separe lo que Dios ha unido" (Mc. 10,9) y, de otra parte, se intenta tomar en consideración la fragilidad humana que Mateo $(5,32$ y 19,9) y Pablo (I. Cor. 7,15) tuvieron presente. El II Milenio a causa de una cierta 'fijación' podría considerarse como un 'paréntesis' en este sentido.

- En segundo lugar, la apertura del Concilio Vaticano II a la categoría de la conciencia ética ( $G S .16$ y $D H .1$ ) ha operado dentro de la teología del matrimonio un giro de 180 grados: como había anotado H. Légaré, a partir del Sínodo (1980) se ha pasado de una filosofía 'esencialista' a una filosofía 'existencial y personalista; antes se pensaba que las cosas habían sido hechas perfectas y en forma definitiva; hoy, en virtud del principio de la

${ }^{63}$ Cfr. Giovanni CERETI, Divorziati risposati. Un nuovo inizio è possibile?......, 98; COMMISSIONE DI STUdio NOMINATA DALla FEDERAZIONE LUTERANA MONDIALE E DAL SEGRETARIATO PER L'UNIONE DEI CRISTIANI, “Teologia dei matrimoni interconfessionali", en Enchiridion Oecumenicum, vol. I, EDB, Bologna 1986, nn. 1759-1871.

${ }^{64}$ Cfr. GIOVANNI PAOLO II, "Il matrimonio sacramentale rato e consumato non può mai essere sciolto neppure dalla potestà del Romano Pontefice", en Insegnamenti di Giovanni Paolo II, vol. XXIII/1 2000, Editrice Vaticana 2002, 101-108; Basilio PETRÀ, "Facoltà del Romano Pontefice e matrimonio rato e consumato", Rivista di Teologia Morale 32/126 (2000) 247-256. 
'gradualidad' la visión es diversa: como enseñaba Juan Pablo II en la $\mathrm{Fa}$ miliaris consortio (34) "el hombre es un ser histórico que se construye día a día con sus opciones numerosas y libres".

En esta perspectiva la conciencia ética adquiere un relieve especial: como afirma la Gaudium et spes "la fidelidad a esta conciencia une a los cristianos con los demás hombres para buscar la verdad y resolver con acierto los numerosos problemas morales que se presentan al individuo y a la sociedad" (16). Como se ha puesto de presente en páginas anteriores, el mismo Benedicto XVI ha insinuado que "en principio no parece que se deba excluir la posibilidad de aplicar la epiqueya en el fuero interno cuando se trata de decidir sobre la nulidad de un determinado matrimonio.

- En tercer lugar, con Vaticano II se comenzó a dar a relieve a 'la vocación conyugal' ( $L G .31$ y GS. 48 y 52), una categoría que en las Comunidades Protestantes había sido reconocida desde el principio de la Reforma; cada uno ha sido llamado desde su propio estado de vida a la perfección cristiana. Frente a los problemas que suscita el divorcio, a veces se tiene la impresión de que la Iglesia Católica quiera imponer la vocación de la continencia a quien se ha divorciado; la recomendación que se hacía a los divorciados vueltos a casar, hasta hace poco tiempo, de 'vivir como hermano y hermana' si quería acercarse a los Sacramentos de la Penitencia y de la Eucaristía, es una prueba.

Durante el Concilio Vaticano II el Vicario Patriarcal Melquita E. Zoghbi había reprochado el hecho de que la castidad perpetua, un estado de perfección cristiana, se imponga como castigo al cónyuge inocente so pena de condenación. En la Iglesia Ortodoxa y en las Comunidades Protestantes se le autoriza al cónyuge divorciado un segundo matrimonio, después de hacer penitencia, para que pueda realizar la unidad que, según el designio de Dios, no logró en un primer matrimonio.

- En cuarto lugar, a partir de la encíclica Dives in misericordia, de Juan Pablo II (1980) la benignidad ha entrado en la teología como exigencia del 'nuevo éthos evangélico'(n. 3); un 'ethos' que tiene aplicación concreta "entre aquellos que están más cercanos" como los esposos, los padres e hijos (n. 14). La Iglesia Ortodoxa con el principio de la 'economía eclesiástica' y las Comunidades Protestantes con el principio de la 'transacción ética' hacen uso de la misericordia divina en favor de los divorciados.

Precisamente, en el Sínodo de la Familia (1980) una de 'las 43 Proposiciones' enviadas al Papa para elaborar la Exhortación Apostólica post-sinodal sugería que se ponga en obra una investigación cuidadosa, dentro de 
la teología católica, teniendo en cuenta la práctica de la Iglesia Oriental a fin de que se haga efectiva la misericordia pastoral.

Junto con la solicitud de recuperar la misericordia evangélica, se debe hacer alusión a otra solicitud planteada por Pablo VI a la Rota Romana durante su pontificado; en dos ocasiones (29 Enero 1970 y 8 Febrero 1973) (65 $^{6}$ el Papa urgió a la Rota Romana restablecer dentro de la jurisprudencia eclesiástica la categoría de la 'equidad canónica'; la definía con palabras del 'Hostiensis' como 'la mitigación del rigor de la justicia con el dulce sabor de la misericordia' ("justitia dulcore misericordiae temperata").

'Misericordia' y 'Equidad' hacen un binomio especial que equivale al binomio bíblico 'verdad y amor' (los dos atributos de Dios) ${ }^{66}$ : este binomio estaba a la base de la alianza de Yahvé con su pueblo, que Israel lo tenía muy presente en su plegaria con los salmos. El Magisterio de la iglesia, especialmente Juan Pablo II y Benedicto XVI han acudido frecuentemente a este binomio para proponerlo como 'paradigma' de la reflexión y de la acción pastoral de la iglesia ${ }^{67}$.

A más de 40 de la exhortación de Pablo VI y más de 30 años de la promulgación de la encíclica Dives in misericordia de Juan Pablo II, la reflexión teológica sobre la equidad canónica y sobre la benignidad pastoral a nivel teórico ha sido relativamente abundante, pero a nivel práctico-pastoral aún hay mucho terreno por ganar. Parecería que la 'recepción' plena de la equidad y de la misericordia, de modo especial dentro de la teología católica del matrimonio, todavía está por realizar.

${ }^{65}$ Cfr. PAOLO VI, "Libertà e autorità, valori essenziali inscindibili" en Insegnamenti di Paolo VI, vol. VIII 1970, Poliglotta Vaticana 1971, 83; IDEM, "Natura e valore pastorale delle norme giuridiche nella chiesa", en Insegnamenti di Paolo VI, vol. XI, 1973, Poliglotta Vaticana $1974,127$.

${ }^{66}$ Cfr. Félix AsEncio, Misericordia et Veritas. El Hesed y Emet divinos. Su influjo religioso-social en la historia de Israel, Aedes Universitatis Gregorianae, Romae 1949.

${ }^{67}$ Cfr. J. Silvio Botero G., "La Verdad y el Amor: presencia de un binomio en la S. Escritura y en el Magisterio", Studia Moralia 49 (2002) 425-465. 